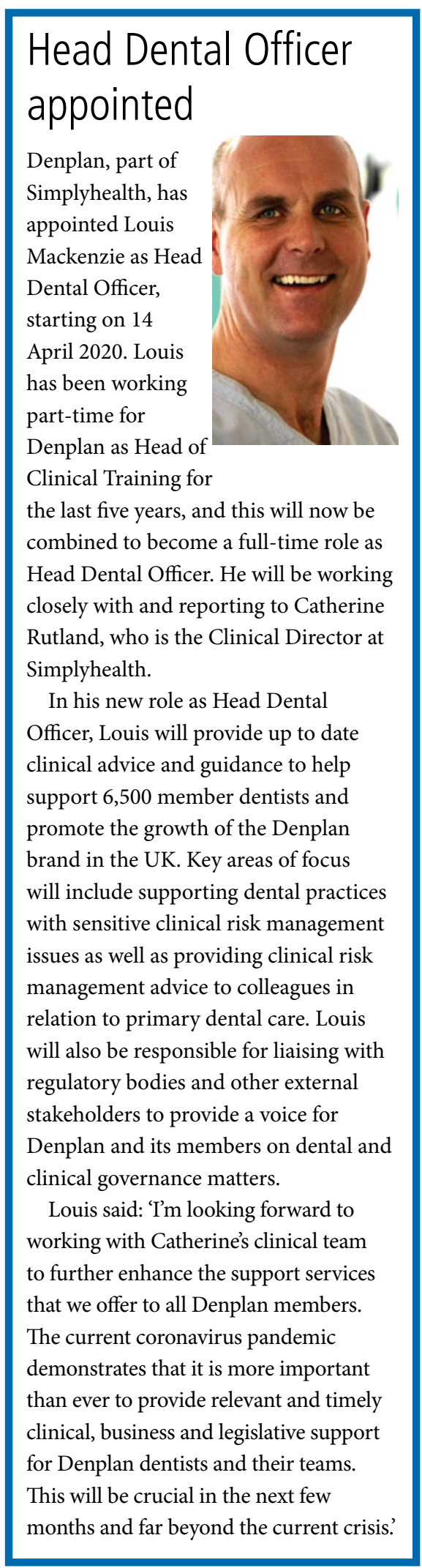

\section{Professor Emeritus J. D. Eccles}

We regret to announce the death on 3 April 2020 of Professor Emeritus J. D. Eccles.

PERSONAL ACCOUNT

\title{
'We are all awaiting our call to the frontline'
}

\author{
By Beth Bradley, Bradford, UK
}

\section{S everal short weeks ago during a busy day in general practice, we were discussing the new 'COVID-19' story} that had appeared on our newsfeeds. We sympathised with its devastating effects but consoled ourselves with the fact it was miles away in Wuhan, China. There was no way anything like that could happen here. We went about our lives as normal, caring for and treating our patients as we always do, knowing we were well protected by our personal protective armour. As time passed cases were reported closer and closer to home: France, Italy, Ireland and then the UK. Suddenly our assurance that 'all would be well' dissipated.

I'm currently a foundation dentist from Ireland working in Bradford; being so far apart from family at this time is a huge worry. My dad as a kidney transplant recipient is 'high risk' and as I write this has been isolating alone for nearly three weeks. I also realised that, although trivial in the circumstances, all hopes of an Easter at home with family would vanish. Not only would it be risky to travel, but as a health professional the possibility of carrying this deadly virus home is a risk I am not willing to take.

All of a sudden the protection of our 'dentistry bubble' is wavering; it is not possible to treat patients within the recommend two metre social distance. Our regular hand washing, PPE and cross infection control procedures are not enough. I was worried going to work that I would contract the virus and unknowingly pass it on to my patients. When the government announced that over-70s were to stay at home, many of my patients were defiant and reluctant, turning up for appointments despite the unambiguous advice. Guidelines are regularly released but these are changing daily. No sooner is advice provided than it is discarded and deemed out of date. It is difficult to process what are and are not safe practices for myself and my patients.

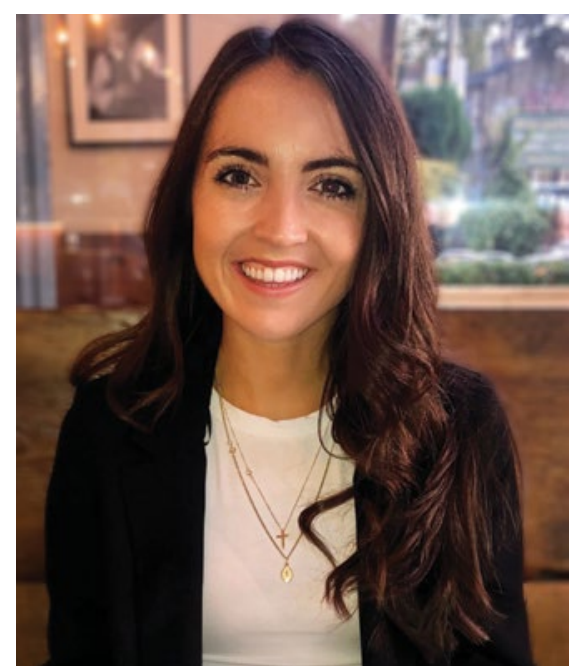

I was relieved when the time came to \#DOWNDRILLS and this trending approach displayed a united front within the dental community. I am finding the restrictions on what we can feasibly do for our patients difficult, and doubt that many of us feel that telephone advice for toothache is sufficient. I eagerly await the opening of local urgent dental care centres. I know I will greatly appreciate the daily face-to-face contact I have with my patients and colleagues when we have safely negotiated this storm.

As a foundation dentist redeployment has been mentioned and is inevitable; we are all awaiting our call to the frontline. I am ready to put whatever skills I can into action, but for now I look to the positives of this situation. Communicating through online platforms has become the norm for work, recreation and relationships. Catching up with friends has never been easier and family members have suddenly learned how to use their phones! We are more in touch than ever. We have slowed down, built resilience, adapted to our enforced circumstances and discovered what matters most.

I personally can take inspiration from Winston Churchill when he said: 'We make a living by what we get, but we make a life by what we give'. 